\title{
Transição econômica para o retorno aos News \\ Commons
}

Economic transition to return to new commons

Transition économique pour revenir à nouveaux communs

Transición económica para volver a nuevos bienes comunes

\section{Daniel Francisco Nagao Menezes}

\section{QpenEdition}

Journals

\section{Edição electrónica}

URL: http://journals.openedition.org/espacoeconomia/18497

DOI: 10.4000/espacoeconomia.18497

ISSN: 2317-7837

\section{Editora}

Núcleo de Pesquisa Espaço \& Economia

\section{Refêrencia eletrónica}

Daniel Francisco Nagao Menezes, «Transição econômica para o retorno aos News Commons», Espaço e Economia [Online], 20 | 2020, posto online no dia 29 dezembro 2020, consultado o 29 janeiro 2021. URL: http://journals.openedition.org/espacoeconomia/18497 ; DOI: https://doi.org/10.4000/ espacoeconomia.18497

Este documento foi criado de forma automática no dia 29 janeiro 2021.

\section{cc) (1) (ㅇ)}

Espaço e Economia - Revista brasileira de geografia econômica est mise à disposition selon les termes de la licence Creative Commons Attribution - Pas d'Utilisation Commerciale - Partage dans les Mêmes Conditions 4.0 International. 


\title{
Transição econômica para o retorno aos News Commons
}

\author{
Economic transition to return to new commons \\ Transition économique pour revenir à nouveaux communs \\ Transición económica para volver a nuevos bienes comunes \\ Daniel Francisco Nagao Menezes
}

\section{Introdução - É possível democratizar a economia?}

1 A economia é uma construção material e cultural que atrai nossas sociedades, nossas democracias. No desenvolvimento contemporâneo de nossos meios de subsistência, as culturas sociais (espaços de autogestão das necessidades básicas) estão em crise. É verdade que eles subsistem e preenchem nossos espaços temporários com redes diárias de apoio, formas de troca em que o dinheiro não medeia ou coopera estratégias para acessar transporte ou serviço Wi-Fi. Mas a economia especulativa se impõe e nos impõe uma reversão climática pela mão de um "progresso" que caminha "triunfante" sob um capitalismo globalizado.

2 Nesse contexto, as 150 maiores empresas do planeta excedem em muito os estados centrais em poder econômico e organização produtiva e podem até desafiá-las legalmente por meio de tratados internacionais patrocinados pela Organização Mundial do Comércio que lhes concedem direitos acima de seus limites constitucionais e legais. Globalização eminentemente financeira, onde $75 \%$ das empresas que controlam $40 \%$ do tecido corporativo global são grupos financeiros. Esse fato também é motivado pelo planejamento capitalista de estado igualmente insustentável que a China representa hoje. Essa construção é altamente conflitante. E não apenas por seus impactos materiais mais óbvios. É também devido aos seus epistemicidas ou erosão do conhecimento social (Sousa Santos, 2009); pela corrosão de seus laços sociais (Sennett, 2000); e pela constante invisibilidade das bases materiais e reprodutivas de nossas economias (Federicci 2004, Carrasco et. ali., 2011). Nesse contexto, o campo das economias-outras 
problematiza conjuntamente questões de poder (quem decide? Que práticas são oferecidas como plausíveis?) E sustentabilidade (como continuar vivendo neste planeta pensando nas gerações futuras, nas espécies à nossa volta?) (Calle, Piñeiro, Suriñach , 2017). Eles reivindicam um espaço de suas contribuições para desenvolver outras visões:

3 - a economia social e solidária nos dá uma visão em termos de democratização e cooperativismo;

4 - a economia do cuidado mergulhará nas bases reprodutivas (corpo, mediações, suportes) que os humanos precisam para sobreviver com dignidade;

5 - a economia ecológica enquadrará nossas atividades no contexto de um planeta que nos permite existir graças à estabilidade de certos guarda-chuvas vitais (água, ar, nitrogênio, temperatura, camada de ozônio etc.);

6 - desde a perspectiva dos "bens comuns" ou dos "novos bens comuns globais", verificaremos a importância atual e histórica das economias baseadas na comunidade ou que desenvolvem fortes laços para cuidar de um bem material ou social.

7 Suas contribuições são eminentemente práticas, pois, por um lado, permitem que o restante das economias percebidas como fundamentais hoje (produtivo-industrial, redistributivo do estado, financeiro e especulativo) subsista. E, por outro lado, desenvolvem laboratórios para implementar outros princípios econômicos e atender às necessidades (regulação corporal, social e ecossistêmica) que nos impedem de colapsar ainda mais em tempos de crise. Por exemplo, diante da crise econômica desencadeada na década de 2010, a economia social e solidária se revelou uma alternativa plausível e desejável. Na Espanha e na Europa em geral, resistiu melhor em termos de destruição de empregos, promoveu economias menos poluentes e proporciona coesão social onde o neoliberalismo destrói os laços sociais.

8 Com base nessas práticas, verificamos como as experiências das outras economias estão se comprometendo radicalmente com a recuperação dos laços sociais, o estabelecimento nos territórios para criar sinergias econômicas e produtivas, a problematização do cuidado como horizonte interno de sua atividade, mas também de sociedade como um todo. Eles enfatizam as características do cooperativismo social presente na Economia Social e Solidária, abordando a tradição dos bens comuns tradicionais, mas renovando a aparência e se adaptando a outros contextos. Eles compartilham o diagnóstico de um capitalismo insustentável que é cada vez mais instalado com base em cercos globais: monopólios sobre ativos naturais, como água, biodiversidade ou o uso dos mares e dos nossos céus; ou em espaços sociais como redes de distribuição, terras para cultivar ou a capacidade de financiar políticas públicas e até a mera possibilidade de intervir na política institucional (Subirtas, Rendueles, 2015; Calle, 2015).

9 Frente a estas limitações, considero as estratégias das Economias-outras podem ser consideradas, dentro de uma grande diversidade de abordagens e contextos, uma expressão do New Commons que procura separar a sociedade e a economia da elite neoliberal, cada vez mais autoritária. Os novos bens comuns são os antigos comunais que ainda persistem administrando coletivamente territórios (florestas, campos, bacias hidrográficas) ou ativos naturais (água, biodiversidade, bancos de pesca). E também são novas iniciativas em questões como alimentação, energia, educação, serviços ou transporte, desde uma prática de gerenciamento compartilhado, até economias 
ecológicas, de assistência, comunitária ou social e de solidariedade. São guildas de pescadores, comunidades de irrigação, redes de sementes, operadores de telecomunicações que fornecem suporte a uma comunidade ou wi-fi local, cooperativas artesanais ou industriais gerenciadas por associações de trabalhadores manuais ou pastores tradicionais, grupos educacionais ou de criação que atendam às necessidades das crianças menores, pessoas que organizam mercados locais ou promovem redes agroecológicas que buscam cuidar de um território e uma maneira saudável de se alimentar, etc. (Comunaria 2017 e VV.AA 2015).

10 Estigmatizado pela fé cega nos mercados capitalistas, J. Rifkin (2014, p. 200) lembra que, graças a seus protocolos de autorregulação e ao acordo sobre instrumentos de controle e punição, esses "bens comuns" sofreram na história. No entanto, eles foram descritos como "el malo de la película, como el responsable de que se desatara la codicia y la destrucción en la Edad Moderna, cuando lo que condujo al pillaje de los recursos y a la explotación de la humanidad más desfavorecida durante los siglos XVIII, XIX y XX, fueron los excesos de un sistema capitalista". Hoje, o ataque à tradição dos "bens comuns" tem mais a ver, como veremos a seguir, com o surgimento de plataformas "colaborativas", que controlam grandes quantidades de canais de vendas, hospedagem, serviços ou transporte, em o que foi reconhecido como wikieconomy (Tapscott, Williams, 2007).

11 O objetivo do texto é analisar através da revisão bibliográfica se a sociedade atual passa por um processo de transição econômica para uma nova forma de commons, estruturados a partir dos mesmos princípios ancestrais e adaptado a realidade atual. Dessa forma o artigo contextualiza inicialmente as mudanças pela qual o mundo passa, abordando o conceito e significa do New Commons, debando a cooperação e solidariedades atuais, concluindo que a transição para esta nova economia é uma alternativa para a crise social e economia que vivemos atualmente.

\section{O que propõe os Novos Commons?}

12 Os New Commons são processos sociais que cuidam da reprodução de bens naturais (físicos, ciclos de vida) ou bens cooperativos (culturais, espaços para compartilhar e cooperar) por meio de uma organização de laços sociais que visam as comunidadesalvo, fornecendo regras para que certos ativos continuam a se reproduzir e a estar disponíveis para essa comunidade ou para uma comunidade mais ampla. Eles não são filhos da Uber, Amazon, Facebook ou Booking, porque a decisão foi tomada e a reprodução escapa à lógica do benefício máximo, independentemente dos impactos ambientais e sociais. Eles não se encaixam, não totalmente, nas iniciativas comunitárias históricas que Ostrom (2010) analisou no "The Government of the Commons". Eles introduzem nuances e atualizam propostas em tempos de ruptura civilizatória:

13 - não estamos falando apenas de "recursos físicos", mas de construção de cultura e vínculos;

14 - geralmente respondem a práticas de democratização de baixo (um forte papel social) ao invés de ideias de ordem e autarquia local (comunidades históricas, essencialistas);

15 - criam direitos na prática (alimentação, energia, cultura) e, em alguns casos, estão abertos a processos de co-gestão, redefinindo o papel do gerente de Estado em relação a iniciativas que estabelecem o que é comunidade pública; 
16 - não emergem como cooperativas formalizadas de trabalho dentro das estreitas margens capitalistas, mas como novos satisfatores que atendem de maneira abrangente às necessidades básicas (material, afetiva, expressiva e de um relacionamento sustentável com a natureza).

17 Se a emergência climática e a urgência por razões de justiça social endossam o porquê de olhar para essas outras economias, pensamos que sua contribuição em termos de criação de esferas da comunidade pública é uma contribuição essencial para redefinir a política em direção ao comum, da radicalização democracia e a necessária realocação de nossas economias. Do ponto de vista feminista, e como forma de contribuir para romper o conflito "entre capital e vida", Pérez-Orozco (2014, p. 264) afirma:

"Lo público ha de romper con la disyuntiva entre el aparato administrativo burocrático y la autogestión: han de ensayarse fórmulas de participación real en los servicios públicos que, además de abrir canales de conectividad con la gente, doten de solidez institucional y amplio radio de acción y coordinación a la voluntad de autogestión y/o participación comunitaria"

18 Em suma, os New Commons compartilham características fundamentais de iniciativas comuns focadas em sustentar sociedades locais e ativos naturais: eles definem limites, estabelecem especificamente quais ativos naturais ou cooperativos eles querem reproduzir, constroem regras e monitoram o processo coletivamente, têm o objetivo de aninhando-se para cima, como analisaremos mais adiante, buscam não alterar os princípios em suas articulações com outros projetos ou em seus saltos de escala (para cima e para os lados, em direção a outras formas de economias mais sustentáveis presentes nos territórios). São híbridos, e as administrações podem aparecer sob a égide da co-gestão pública ou são estimuladas pelas comunidades de trabalho ou grupos de interesse. Por exemplo, grande parte das inovações sociais derivadas de políticas municipais no Brasil, como cantinas públicas, mercados solidários ou estratégias comunitárias para obter energia mais sustentável, são devidas a uma inovação social participativa conjunta entre produtores, consumidores e administração pública (Fernández, Piñeiro, 2019).

19 Eles combinam a abertura da agenda e a gestão de iniciativas de políticas locais com estratégias sociais que permitem autonomia para seus participantes: a sala de jantar, o mercado ou a produção de alimentos ou energia tem mais a ver com princípios e dinâmicas da sociedade existente e não vinculado de maneira subordinada às administrações. A Wikipedia opera do "acesso livre" à informação, embora os filtros e regras que governam a referida fundação apoiem uma comunidade em mudança de promotores, editores e emissoras que funcionam como um novo conhecimento e conhecimento comum com uso de novas tecnologias (Ortega, Rodríguez, 2011). Quando nos referimos ao New Commons, estamos falando de processos claramente comprometidos com a democratização, para garantir certos direitos de uso de bens, a um processo que vai além da agregação e gera laços sociais, a uma aposta que reverte para o exterior em reivindicações por justiça social e sustentabilidade.

20 E não há dúvida de que, para sair de uma perspectiva eurocêntrica, as políticas inspiradas nos comunais ou em um novo "bem comum" são mais importantes e têm aspectos culturais mais significativos em territórios considerados periféricos pela economia globalizada (Sousa, Avritzer, 2004). São as bases indígenas, camponesas e ejidos presentes na agroecologia ou no município mexicano, por exemplo. Essas são as propostas sociais das economias-outras que partem da concepção comunitária do 
território ao longo dos Andes ou em grande parte dos territórios da África subsaariana, práticas de trabalho cooperativo, como mingas no ayllús boliviano ou nos espaços liberados em tempos de escravidão e que hoje compõem os quilombos no Brasil. Acrescentaríamos grande parte da tradição indiana que caracterizou o debate e as práticas do que hoje entendemos como desenvolvimento endógeno ou democracia na Terra. Ou as propostas baseadas na concepção de uma família extensa que se governa em solidariedade, os ujamaa que Julius Nyerere $(1966 ; 1973)$ cunhou mais tarde como base do socialismo na África.

21 Aqui compilo, com base na minha experiência e nas sistematizações de outros pesquisadores ${ }^{1}$, uma visão prática desses New Commons e como eles operam para criar essas economias a partir de baixo, bebendo dessa tradição cooperativa de bens comuns tradicionais, do mundo do trabalho que aposta na autonomia produtiva e pelas críticas e propostas advindas da economia do cuidado. Experiências ancoradas na esfera social, mas que não fogem do apoio à transformação de municipalismo ou co-gestão, apoio entre instituições públicas locais e processos institucionais da cidadania ou do tecido (re)produtivo. São gradualmente tecidas, portanto, entre as âncoras políticas da gestão/co-gestão/autogestão, sempre com ênfase no público, embora desta vez sujeitas às regras de sustentabilidade mais típicas do governo dos bens comuns.

As iniciativas do New Commons correspondem às práticas de cogerenciamento e autogerenciamento descritas acima. A administração para com os "comuns" funcionaria como um guarda-chuva político que facilita a participação e a ação a partir de baixo. São projetos que buscam abrir instituições (existentes ou de criação social recente) para poderem enfrentar a construção de economias - outras desde o início do New Commons. Iniciativas que são em si uma rede de satisfatores que desencadeiam ou exigem sinergias políticas. Por exemplo, o direito à alimentação e nutrição saudáveis e apropriadas deve estar enraizado na soberania alimentar na prática, uma decisão e compromisso de produzir e distribuir no mesmo território. Que está intimamente ligado a outras políticas urbanas que incluem como equipamento o direito de produzir e comercializar localmente. 0 que, por sua vez, está relacionado à promoção de uma economia social e solidária no território ou a uma visão feminista de nossas práticas de consumo que quebram as desigualdades nas casas e no acesso à propriedade de terras ou mercados.

23 O New Commons é uma consequência e, ao mesmo tempo, um choque, para que as maiorias sociais possam experimentar a partir da qual princípios e práticas econômicas podem ser realocados e fortalecer os laços sociais diante de uma transição inevitável. Não os concebemos como um projeto político delineado. Tanto os precursores da ideia do keynesianismo verde quanto os de uma diminuição justa concordam que trazem melhores princípios e mais bem-estar. Entre os primeiros, Jackson (2017, p. 165) afirma, em relação a essas iniciativas de autogestão social e cogestão da comunidade pública, que são economias que nos trazem mais felicidade, segundo várias pesquisas, sem apostar no crescimento material contínuo, buscando construir um "espaço seguro de operações" para a humanidade. São inovações que ainda estão subvalorizadas, mas o futuro está no possível (por mais complexo que seja o caminho) e nunca no impossível (que deve atender a limites ambientais inabaláveis, crescimento monetário e injustiça social). 


\section{Realmente cooperamos? Redes de clientes X New Commons}

24 Nem tudo o que é considerado "colaborativo" brilha através do prisma da "cooperação social". O capitalismo, alinhado com outros eixos de poder (patriarcado, autoritarismo, colonialismo), é suportado por hardware (infraestruturas, arranjos territoriais, instituições) e software (cultura, legitimidade, comunicação de massa) que o alimentam. Toda crise convida à reinvenção dos canais de apropriação. Mas também das formas de obter consentimento social, o apoio em muitos casos da grande maioria da população. Lá, as alternativas podem ser fornecedoras, consciente ou inconscientemente, de combustível para o fogo: idiomas que falam de cooperação quando representam auto exploração ou uma relação de trabalho sem direitos; mercados controlados por multinacionais portadoras do adjetivo social; aplicações tendenciosas do que significa reduzir a pegada ecológica como o quilômetro zero.

25 Atualmente, o capitalismo está avançando na colonização de enclaves físicos e culturais típicos, até agora, de outras economias. Torna-se "verde", "cooperativo", com sensibilidade "feminista", "libertária" e, ocasionalmente, "solidária". Podemos atestar que esse não é o caso, uma vez que os dados apontam e as percepções mostram que é menos sustentável, mais corrosivo para os laços sociais, fortemente enraizado nas práticas patriarcais, a força motriz por trás do cinismo individualista e, abertamente, inoportuno (Prats, Herrero, Torrego, 2016). Mas o poder funciona desenvolvendo um "consentimento sem consentimento" que Noam Chomsky diria, uma persuasão combinada com sanções.

26 Existem pelo menos três economias que disputam o sobrenome "social", até então mais típico de outras economias, a saber:

27 - Capitalismo uberizado, que avança em compartimentos vitais com o envolvimento dos cidadãos agora transformados em clientes. Economia neoliberal que consegue "se livrar" da sociedade e avança com a constante inovação tecnológica. Exemplos: plataformas que servem como um link específico entre "freelancers" e clientes para o transporte de pessoas, mercadorias, venda de vagas em hotel, compra de um pacote de férias ou, como a Amazon, abertura de um shopping globalizado pela Internet e sem obrigações com fornecedores ou trabalhadores;

28 - Expressões de base mais social, como economia capitalista "ecológica", em muitos casos com roupagens da comunidade ou incorporadas em dinâmicas de serviço público terceirizadas devido a ajustes neoliberais. Eles insistem em colocar o mercado como referência para a ação social. Os mercados existem para levar em conta as necessidades sociais e quantificar os impactos ambientais. Exemplos do acima exposto são: o cooperativismo como uma mera fórmula legal que às vezes serve para terceirizar serviços estatais ou como meras estratégias precárias de sobrevivência ou integração social; iniciativas que colocam o preço ou o mercado como motor da comunidade, como na descrição de Christian Felber (2015) sobre a Economia para o Bem Comum, mas não práticas que apontem para uma realocação social dos mercados; espaços para compra e venda onde a plataforma governa filtros e formas de troca;

29 - Economias sociais e solidárias que apontam para a gestação do New Commons. Aqui, o econômico não circula "fora" do Estado ou dos grandes mercados globalizados, mas está sujeito a necessidades sociais e limites ambientais. Eles contemplam uma 
gradualidade de opções práticas que se movem entre a co-gestão pública (a administração atua como um guarda-chuva e a social como dinamizadora) e a autogestão (a autonomia social é importante o suficiente para manter os princípios do projeto). A comunidade pública é estabelecida como um dos pilares da saída da crise socioambiental, sem comprometer o direito a ter direitos (público-normativo). Entende-se que a ação democratizante é muito relevante diante da rigidez, verticalidade e pouca atenção ao contexto que deriva da dinâmica capitalista inserida na esfera do estado público ou da depredação derivada de parcerias públicoempresariais que são uma fonte de negócios para grandes empresas transnacionais.

30 Como saber o que descobrimos quando alguém nos fala sobre cooperação como elemento fundamental de uma iniciativa econômica? Apenas caracterizamos amplamente essas tipologias que, logicamente, admitem todos os tipos de hibridizações e gradualidades. No entanto, algumas perguntas rápidas nos permitiriam identificar em qual vértice do triângulo anterior (uberização, eco capitalista, New Commons) estamos nos movendo (Calle, Fernández, 2015):

31 - O que queremos "democratizar"? É o acesso a uma oferta cada vez mais vinculada a novas tecnologias que facilitam compras imediatas de crédito, acesso a mercados capitalistas ou a construção de uma transição para sistemas econômicos endógenos mais locais, com uma forte visão de equidade e justiça social?

32 - Que necessidades queremos "satisfazer" e para quem? São bens ou serviços que nos permitem um bem-estar físico e emocional individual e coletivo, de acordo com as limitações impostas pelo ambiente ou são nichos de mercado reservados a algumas elites?

33 - Quais direitos queremos defender e como? As inovações tecnológicas, as de consumo cada vez mais inconsciente ou as de cidadãos com direito a produzir de forma sustentável e a viver com dignidade?

34 - Reivindicamos com esta iniciativa, dentro e fora dela, relações trabalhistas justas e reproduzíveis pela sociedade?

35 A economia, ou melhor, a utilidade das economias para construir uma transição socioambiental mais humana está em disputa. A colonização de sobrenomes "sociais", "cooperativos" e "sustentáveis" de iniciativas ligadas às elites neoliberais tem uma longa história. Isso se reflete em relatórios que ocorrem no final das décadas de $1980 \mathrm{e}$ 1990, preparados pelo Banco Mundial e no início de grandes reuniões, como a Cúpula da Terra, realizada no Rio de Janeiro em 1992, onde debates e disputas ocorrem em torno da crise socioambiental. O "desenvolvimentismo" e mais tarde a chamada "globalização", embora com tons esverdeados, acabam prevalecendo na agenda oficial (Cariño, Castorena 2015).

36 Algo semelhante ao que acontece hoje em ações internacionais destinadas a se estabelecer como referência do que deve ser entendido por uma transição inevitável e como é colaborar com a dinâmica atual da globalização sob os títulos de "economia climática", "resiliência" ou "adaptação". Iniciativas que são desenvolvidas em uma lógica de "transparência" ou "participação". Como mostram os coordenadores do projeto Ciudades en Movimiento (Fernández, Morán, Prats, 2019, p. 77):

"Entre ellas destacan C40, que se dedica a promover la acción climática en grandes ciudades, promovida por el multimillonario y ex alcalde de Nueva York Michael Bloomberg, o 100 Resilient Cities, lanzada desde la Fundación Rockefeller para promover la resiliencia ecológica, económica y social. Madrid participa de C40 y 
Barcelona de 100 Resilient Cities, que temática y formalmente serían redes claramente orientadas a dinamizar transiciones ecosociales; sin embargo, el funcionamiento de estas redes puede ser más problemático por cuestiones como el enfoque de las problemáticas, la transparencia en la rendición de cuentas, los criterios de selección, la asignación de los fondos, la compatibilidad y competencia con redes públicas de ciudades”.

"Governança", "redes de interesse" ou "partes interessadas" são abordagens que buscam orientar ou obter uma fotografia das redes de poder que governam um processo. Promovidos na década de 90 a partir do mundo anglo-saxão e próximos aos grandes instrumentos neoliberais (Banco Mundial, Fundo Monetário Internacional, etc.), acabaram substituindo a gramática da "democracia" entendida como autonomia social ou autogoverno, participação em diferentes níveis institucionais, envolvimento e por fim, o conhecimento sobre questões que nos afetam, como a economia e, especificamente, a transição necessária de nossos metabolismos atualmente insustentáveis. Outras economias enfatizam a sustentabilidade social e ambiental, mas também criticam quem governa o poder-por (redefinição de fins) e poder-com (capacidade de cooperar). O New Commons é um instrumento que, em nível local, onde o território se torna "próximo" (em termos de conhecimento, identidade, articulação), facilita uma combinação de medidas baseadas na democracia radical (autonomia social) e democracia participativa (instituições abertas à cidadania (Calle, 2013; Calle 2015). Porém, o New Commons é uma garantia da construção de processos de transição socioambiental em larga escala com a participação, a recuperação dos laços sociais e a reprodução de ativos natural e cooperativo?

\section{Saída da crise: precisamos muitos planos C's}

O New Commons passa a considerar que a economia capitalista neoliberal quebra as sociedades, dilui nossos costumes comuns, como afirma E. Thompson, e impossibilita ciclos de vida essenciais para a espécie humana. Mas uma outra economia pode ser construída a partir daí nas escalas territorial (sociedade local), estadual (sociedade principal) ou global (humanidade)?

Sempre que falamos de crise, é necessário desenvolver os Planos B's, agendas e linhas de ação que nos tragam "outro modelo" de globalização, de sociedade, de estrutura política. A crise de legitimação e o favorecimento de um instrumento de controle neoliberal na União Europeia (mecanismos de controle orçamentário, políticas do Banco Central Europeu, posições políticas ligadas ao ambiente de atores financeiros como o Goldman Sachs) desencadeou um forte descontentamento (distanciamento) e rejeição entre a população europeia. Em 2016, foi lançado, em escala europeia, por partidos de esquerda e grupos sociais, uma série de conferências sob o lema "Plano B, contra a austeridade, para uma Europa democrática". 0 objetivo era reunir simpatias dos cidadãos e criar sinergias políticas contra as propostas de austeridade e solidariedade que emanam da União Europeia e que os próprios participantes e promotores, como o ex-ministro das Finanças grego Yanis Varoufakis, se colocaram atrás da onda de xenofobia e da ascensão da extrema direita. Mas é difícil criar uma agenda paralela de cima para baixo, sem falar em desafiar as agendas políticas que trazem à tona a economia especulativa de uma maneira que suscite implicações sociais e de apoio. Parece haver apenas um modelo, o resto não existe ou não pode ser A 
agenda neoliberal é legitimada após a sigla TINA: "There is no Alternative", afirmou o primeiro ministro sobre alternativas econômicas de Margaret Thatcher.

40 Implicitamente, o New Commons critica a mera noção de "modelo estabelecido", sem, no entanto, abrir mão de estabelecer princípios e políticas que devem nos guiar em uma transição socioambiental em diferentes níveis. Ao promover debates e visões sobre o que queremos satisfazer e democratizar, juntamente com os direitos e sistemas econômicos que queremos promover (as perguntas feitas anteriormente), o New Commons atravessa a fronteira de seus territórios e sua singularidade específica. Por exemplo, eles espalham a necessidade de introduzir uma visão territorial da economia, práticas de cogestão na política, uma inspiração mais radical (direta) ou participativa (abertura de instituições) nas formas de organização democrática. E sobre valores, eles entendem que da tríade que abrange o feminismo, o ambientalismo e as visões cooperativas (com traços camponeses, marxistas ou libertários), é de onde se pode e deve enfrentar o colapso da civilização. E, além da pedagogia, são realidades locais decisivas para entender como os modelos neoliberais são reproduzidos ou negados (Gibson-Graham 2011, Gago 2015).

41 Há boas razões para pensar que alternativas aos atuais sistemas econômicos não serão legitimadas e serão apoiadas por instrumentos muito acessíveis e favoráveis aos mercados globais e acordos comerciais neoliberais. Pelo contrário, o New Commons nos propõe expandir a dinâmica cooperativa como base para a mudança. Eles são uma condição prévia para futuras economias viáveis e justas, mesmo que agora não sejam o motor da mudança nessa direção. A dinâmica da colaboração entre as políticas de cogerenciamento e autogerenciamento pode ser essencial para a expansão dos planos $C$ 's, ou seja, uma escalada maciça de práticas diante de um colapso social, econômico e ambiental previsível, maior do que as maiorias sociais agora pode sentir.

42 Os Planos C's representariam o prelúdio necessário para os possíveis Planos B's para uma transição solidária e sustentável em diferentes escalas, padrões de vida que vagam e se sobrepõem do mais cotidiano (microssocial) para o territorial (representado por uma bioregião ou pelas fronteiras políticas do país) até atingir o global (planetário). Como confirmar a afirmação anterior? Por cinco razões que abordaremos abaixo e que reivindicam o New Commons como a experiência histórica de toda sociedade, como um mecanismo de mudança, como uma estratégia de articulação social, como ação política e como mera credibilidade em alternativas a um neoliberalismo cada vez mais autoritário.

43 Primeiro, o mundo continua a se reproduzir cuidando e preservando a vida de uma grande parte da população mantendo situações de desigualdades que afetam a maioria da população especialmente nos países pobres e miseráveis, com menos acesso à educação. A alternativa está no apoio das economias centrais, que é fundamental para a cooperação. Esse é o fator C, usando uma expressão de Razeto (1997) para a economia social e solidária, necessária para a reprodução de corpos e padrões sociais. Podemos afirmar que o conjunto de novas comunidades nas estruturas dos Planos $\mathrm{C}$ que, dentro de uma estrutura institucional e de uma imagem favorável, possam inspirar, estabelecer e legitimar alguns Planos B's que nos levam a menos injustiça e interrupção do colapso econômico ao qual caminhamos. As comunas tradicionais ou as novas economias comunitárias que são percebidas, especialmente na América Latina, como a base de novos edifícios construídos a partir de uma auto-organização social que 
sustenta e transborda o Estado como um motor econômico do neoliberalismo (Vega, Martínez, Paredes, 2018).

Em segundo lugar, o New Commons é o laboratório atual de princípios que podem inspirar uma diminuição (decrescimento) com justiça. Muitas das iniciativas descritas no New Commons nos ajudam a pensar e executar como "desmontar" a dinâmica atual do colapso. As propostas de cogestão e autogestão que vimos anteriormente combinam como apoio e inspiração as medidas decrescentes necessárias. Como Herrero e González (2011, p. 42) afirmam:

“¿En qué hay que decrecer? Reducir el tamaño de una esfera económica no es una opción que podamos escoger. El agotamiento del petróleo y de los minerales, y el cambio climático van a obligar a ello. Esta adaptación puede producirse por la vía de la pelea feroz por los recursos decrecientes, o mediante un reajuste colectivo con criterios de equidad. El decrecimiento puede abordarse desde prácticas individuales, comunitarias y también a nivel macro".

Entre as medidas macroeconômicas que visam colocar limitações e desmantelar a barbárie, estariam: impor limites às indústrias que contrariam a vida (defesa), ancorar moedas a valores físicos vinculados a alimentos básicos, minerais estratégicos ou tamanho da população, impedindo a os bancos especulam com dinheiro que não se reflete em depósitos, estabelecimento de ecotaxas para setores que estão em desacordo com a saúde das pessoas e do planeta. Eles também apontam medidas que incentivariam a construção direta de outras economias: controle participativo público (trabalhadores e cidadãos) de setores-chave, como bancos, energia, educação ou alimentos, aumentando o uso e acesso a energias renováveis, promovendo o transporte público e o planejamento urbano, adaptou-se as questões bioclimáticas às crises com objetivo de garantir o direito à alimentação e moradia, entre outros. Ou seja, desmontar de cima exige a presença ativa do New Commons operando de baixo.

46 Terceiro, o New Commons promove articulações intersetoriais, que são embriões de economias que emergem de iniciativas particulares para promover dinâmicas de cooperação entre economias mais complexas ou que abordam a satisfação das necessidades humanas de uma maneira mais abrangente. Por exemplo, a agroecologia combina produção sustentável, defesa de um território e questões de saúde, bem como a promoção de economias locais. Ao fazer isso, o New Commons ganha potencial para aumentar "para cima" e "para os lados". Subir de lado, com base em uma experiência específica, consistiria em promover uma maior implantação territorial e uma maior conexão com outras iniciativas econômicas (monetizadas ou não) próximas, geográfica e tematicamente, da experiência dado. Subir implicaria o desenvolvimento de legitimidades, instituições e agendas capazes de transformar nossas economias em planos macro-sociais.

47 Como Elinor Ostrom alegou, a capacidade de gerar adesão e funcionar para a sustentabilidade dos bens comuns tradicionais residia em sua capacidade de se replicar e aninhar. Duas formas de rearticulação de acordo com o objetivo perseguido. Por "aninhamento", entendemos a criação de estruturas superiores, como uma comunidade de irrigadores que se associa para criar uma rede de co-gerenciamento em uma bacia hidrográfica, que continua a manter princípios de distribuição de energia e sustentabilidade, embora adaptados a uma dimensão representativa e, onde as decisões estratégicas sempre têm a legitimidade das experiências fornecidas abaixo. E por "replicação" teríamos o exemplo da criação de instituições de gestão comunitária da água que funcionam autonomamente em outras bacias. 
48 Atualmente, existem 700.000 cooperativas que agrupam $12 \%$ da população mundial. Eles estão distribuídos em centenas de países e representam, em muitos casos, uma parte significativa do PIB. Não são experiências idílicas sem problemas, nem impediram que as relações capitalistas sejam hegemônicas. Mas eles demonstram, como sugere a poeta portuguesa Sophia de Mello Breyner, que há um rumor de floresta no pequeno jardim.

49 A interoperação territorial é, no entanto, um dos déficits que esses New Commons enfrentam em seus desafios da economia neoliberal em nível macro-social. Por exemplo, existem iniciativas bem conhecidas no Estado espanhol, como a Coop57 e, no entanto, estamos testemunhando uma falta de fluxo de liquidez para processos de transformação. Conhecemos pomares agroecológicos em nossas cidades que, em muitos casos, funcionarão como ilhas afastadas de uma problematização do direito à alimentação na cidade.

50 Quarto, o New Commons facilita a "separação" das sociedades da economia neoliberal. São, portanto, experiências para uma "política do comum". Eles propõem uma redistribuição radical do poder político e econômico, como argumenta M. Eugenia Rodríguez Palop (2019, p. 89) a partir de uma perspectiva ecofeminista:

"Lo común apela a la necesidad de reconstruir los vínculos que nos liberan, a una filosofía relacional que interioriza tanto nuestra radical vulnerabilidad como la normalidad de la inter-ecodependencia [...] en una la política de lo común, la defensa de los derechos sociales no se plantea obviando el elemento comunitario y democrático que los sustenta, porque una sociedad igualitaria, con derecho a la educación, la sanidad o la vivienda, sin un proceso de radicalización de la democrática, es una sociedad clientelar"

51 Eles constroem formas de participação e redistribuição econômica: cooperativas de crédito, planejamento espacial usando critérios de camponeses. As formas de governo autônomo em torno de recursos (bens) e serviços que são e serão mais essenciais em um contexto de mudança climática estão aumentando: municipalização ou gestão comunitária da água, promoção da saúde com foco comunitário e não farmacêutico. Eles sustentam direitos: iniciativas agroecológicas para colocar em prática uma soberania alimentar, um direito à alimentação e nutrição saudáveis, de acordo com os limites, necessidades e culturas de cada território ou bioregião; plataformas de aprendizado e conhecimento elaboradas coletivamente e acessíveis a mais população, com o objetivo de interromper os epistemicidas e defender o conhecimento popular e tradicional e as formas de sistematização decorrentes de uma complexa ciência social. Tornam-se enredados, articulados e apresentam desafios e alternativas em uma escala maior. É o caso das políticas municipais que, entre 2015 e 2019, foram, em muitos casos, vinculadas a iniciativas de autogestão e co-gestão econômica em torno da produção e distribuição de energia, moedas sociais ou criação de plataformas regionais de defesa do território ou de uma economia mais social e solidária. Esses novos direitos, como apontam Rodríguez Palop (2019) ou Vega et. ali (2018), não estão localizados necessariamente como contrários ou fora do Estado.

52 Ao introduzir padrões de cogestão econômica ou radicalização democrática, eles propõem abrir instituições de instâncias locais (municipalismo libertário, seguindo Bookchin e Biehl) e articular democracias de maior escopo e força deliberativa (democracias fortes, nas palavras de Benjamin Barber). O New Commons combate a "experiência de desenraizamento" e a crescente "desintegração social", chaves para entender a ascensão da extrema direita no mundo (Rodríguez Palop, 2018, p. 05). 
53 Finalmente, o New Commons são experiências que dão, de maneira simples e clara, credibilidade à mudança social de baixo, daquilo que foi participado e experimentado. $\mathrm{E}$ isso não é trivial em tempos de grandes histórias, notícias falsas e pessoas enclausuradas em novas tecnologias. Como ocorre em todas as crises, e mais ainda, na busca de pós-desenvolvimento, quando enfrentamos uma transição inevitável (Calle, 2014), é previsível que as culturas sociais (a autogestão das necessidades básicas de uma maneira próxima) aumentem no calor das mudanças climáticas, crises alimentares e outras tempestades políticas que quebram o atual quadro institucional.

54 Isso acontece historicamente quando as crises atingem repentinamente e com força, como foi testemunhado recentemente em Cuba nos anos 90, na Argentina em 2000 e na própria Grécia na década anterior. A dinâmica de choque que, assim como facilita a intervenção abrupta das elites (Klein, 2010), também é capaz de inspirar mudanças de baixo para cima por meio de iniciativas na linha do New Commons (Fernández, Morán, 2019). A questão decisiva é saber que ferramentas a população que enfrentará, quase da noite para o dia, o colapso econômico terá: grupos humanos que cultivam sociedades mais justas e sustentáveis em um determinado território ou propostas que insistem em acelerar o motor para que caia mais rápido no abismo.

55 Existe, portanto, uma nova arena política em construção a partir do conceito de “comum", sustentado em um conjunto de práticas contrárias à estrutura privada das organizações produtivas. Os New Commons, sob esta ótica, podem ser considerados anti- neoliberais, como afirmam Dardot e Laval (2017, p. 25): "explorar essa significação política das lutas contemporâneas contra o neoliberalismo", criando assim uma nova ética política.

\section{Conclusões}

56 Com isso, constata-se que o mundo caminha para uma situação de colapso ambiental e consequentemente econômico, o que se prova com a crise social e econômica da Pandemia de COVID-19, a qual, explicitou a desigualdade social e a incapacidade das instituições e ferramenta existentes, obrigando a humanidade a buscar alternativa para a sobrevivência.

57 Os New Commons se apresentam como uma alternativa imediata e viável, necessitando tão somente a estruturação de processo de transição para alcançar os objetivos elencados ao longo do texto, deixando a sociedade mais próximas dos ideais de justiça e solidariedade, alcançando de imediato a democratização da economia.

\section{BIBLIOGRAFIA}

CALLE, Á. (2013). La Transición inaplazable. Salir de la crisis desde los nuevos sujetos políticos. Barcelona: Icária. 
CALLE, Á; FERNÁNDEZ, J. (2015). Economías sociales y economías para los Bienes Comunes. Otra Economía. Vol. 9 n. 16. Pp. 44-68, janeiro/junho 2015. Disponível em [http://revistas.unisinos.br/ index.php/otraeconomia/article/viewFile/otra.2015.916.04/4676]

CALLE, A.; PIÑEIRO, C.; SURIÑACH R. (2017) Comunes y economías para la sustentabilidad de la vida. in Comunaria (org.). Rebeldías en común - Sobre comunales, nuevos comunes y economías cooperativas. Madrid: Libros en Acción.

CARIÑO, O.; CASTORENA L. (2015). Saberes para la sustentabilidad. Barcelona: Icária.

CARRASCO, C.; BORDERÍAS, C.; TORNS, T. (2011). El trabajo de cuidados. Historia, teoría y políticas. Madrid: Catarata.

DARDOT, P.; LAVAL, C. (2017). Comum: ensaio sobre a revolução no século XXI. São Paulo: Boitempo.

FEDERICI, S. (2004) Calibán y la bruja: Mujeres, cuerpo y acumulación originaria, Madrid: Sueños.

FELBER, Christian (2015). La economía del bien común: Un modelo económico que supera la dicotomía entre capitalismo y comunismo para maximizar el bienestar de nuestra sociedad. Bilbao: Deusto.

FERNÁNDEZ Kois, J. L.; MORÁN, N. (2019) Comunidades cooperativas en tiempos de catástrofe. Revista Ctxt n. 232. Disponível em [https://ctxt.es/ es/20190731/Firmas/27643/Jose-Luis-FdezCasadevante-Nerea-Moran-crisis-ecosocial-comunidades-cooperativas-catastrofes.htm]

FERNÁNDEZ Kois, J. L.; MORÁN N.; PRATS, F. (2019) Ciudades en movimiento. Avances y contradicciones de las políticas municipalistas ante las transiciones ecosociales. Madrid: Foro Transiciones.

FERNÁNDEZ Kois, J. L.; PIÑEIRO, C. (2019). Innovación social y participación ciudadana. en ¿Por qué las ciudades son clave en la transición ecológica?, Informe sostenibilidad 2019. Madrid: Fundación Alternativas.

GAGO, V. (2015). La razón neoliberal. Economías barrocas y pragmática popular. Madrid: Sueños. GIBSON-GRAHAM, J. K. (2011). Una política poscapitalista, Bogotá: Siglo del hombre editores. HERRERO, Y.; GONZÁLEZ REYES, L. (2011) Decrecimiento justo o barbarie. Revista Pueblos, n. 49. JACKSON, T. (2017). Prosperity without Growth. Foundations for the economy of tomorrow. Londres: Routledge.

KLEIN, N. (2010). The Shock Doctrine: The Rise of Disaster Capitalism. New York: Metropolitan Books.

NYERERE, J. (1966). Freedom and Unity: Uhuru na Umoja. London: Oxford University Press.

NYERERE, J. (1973). Freedom and Socialism: Uhuru na Maendeleo. Dar es Salaam: Oxford University Press.

ORTEGA, J. F.; RODRÍGUEZ J. (2011). El potlatch digital: Wikipedia y el triunfo del procomún y el conocimiento compartido. Madrid: Editorial Cátedra.

OSTROM, E. (2010). El gobierno de los comunes. La evolución de las instituciones de acción colectiva. Cidade do México: Fondo de Cultura Económica.

PÉREZ OROZCO, A. (2014). Subversión feminista de la economía. Aportes para un debate sobre el conflicto capital-vida. Madrid: Sueños.

PRATS, F., HERRERO, Y.; TORREGO, A. (2016) La gran encrucijada. Barcelona: Libros en Acción. 
RAZETO, L. (1997) Los Caminos de la Economía de Solidaridad. Buenos Aires: Lumen-Hvmanitas.

RIFKIN, J. (2014) La sociedad de coste marginal cero. El Internet de las cosas, el procomún colaborativo y el eclipse del capitalismo. Barcelona: Paidós.

SENNETT, Richard (2000) La corrosión del carácter. Las consecuencias personales del trabajo en el nuevo capitalismo. Barcelona: Anagrama.

SOUSA SANTOS, B. (2009). Epistemología del sur. CIdade do México: Siglo XXI Editores.

SOUSA SANTOS, B., AVRITZER, L. (2004). Introdução: para ampliar o cânone democrático. in Sousa Santos, B. (org.). Democratizar a democracia. Coimbra: Centro de Estudos Sociais (CES).

TAPSCOTT, D.; WILLIAMS, A. (2007). Wikinomics: La nueva economía de las multitudes inteligentes. Barcelona: Paidós.

VV.AA (2015) El procomún y los bienes comunes. Dossieres EsF ํo 16. Disponível em http:// www.ecosfron.org/wp-content/uploads/DOSSIERES-EsF-16-Elprocom\%C3\%BAn-y-los-bienescomunes.pdf]

VEGA, C.; MARTÍNEZ R.; PAREDES M. (2018) Producir lo común. Entramados comunitarios y luchas por la vida. Madrid: Sueños.

\section{NOTAS}

1. Cf. Fernández, Piñeiro, 2019; Calle, Fernández, 2015.

\section{RESUMOS}

A atual economia capitalista, patriarcal e cada vez mais financiada conta com compartimentos (sociais, ambientais ou de infraestrutura) que reproduzem sua hegemonia e impedem o surgimento de outras visões e práticas econômicas. Diante desses anexos, as estratégias das Outras Economias podem ser consideradas, dentro de uma grande diversidade de abordagens e contextos, uma expressão do New Commons que busca desapoderar a sociedade e a economia da entidade neoliberal e cada vez mais autoritária das elites. Com isso, o artigo tem por objetivo demonstra que os novos bens comuns são os antigos comunais que ainda persistem administrando coletivamente territórios (florestas, prados, bacias hidrográficas) ou ativos naturais (água, biodiversidade, bancos de pesca) e, também são novas iniciativas em questões como alimentação, energia, educação, serviços ou transporte comprometidas, desde uma prática de gerenciamento compartilhado, até economias ecológicas, de assistência, comunitária ou social e de solidariedade. Demonstra-se com a revisão bibliográfica realizada que o retorno aos Commons proposto no texto é uma alternativa para democratização da economia.

The current capitalist, patriarchal and increasingly financed economy has compartments (social, environmental or infrastructure) that reproduce its hegemony and prevent the emergence of other economic views and practices. In view of these annexes, the strategies of the Other Economies can be considered, within a great diversity of approaches and contexts, an expression of the New Commons that seeks to dismantle the society and the economy of the neoliberal and 
increasingly authoritarian entity of the elites. With this, the article aims to demonstrate that the new common goods are the old communal ones that still persist collectively managing territories (forests, meadows, watersheds) or natural assets (water, biodiversity, fishing banks) and are also new initiatives on issues such as compromised food, energy, education, services or transport, from a shared management practice, to ecological, assistance, community or social economies and solidarity. The bibliographic review shows that the return to Commons proposed in the text is an alternative for democratizing the economy.

L'économie capitaliste, patriarcale et de plus en plus financée actuelle comporte des compartiments (sociaux, environnementaux ou infrastructurels) qui reproduisent son hégémonie et empêchent l'émergence d'autres vues et pratiques économiques. Au vu de ces annexes, les stratégies des autres économies peuvent être considérées, au sein d'une grande diversité d'approches et de contextes, comme une expression des nouveaux communs qui cherche à démanteler la société et l'économie de l'entité néolibérale et de plus en plus autoritaire des élites. Avec cela, l'article vise à démontrer que les nouveaux biens communs sont les anciens communaux qui persistent encore à gérer collectivement des territoires (forêts, prairies, bassins versants) ou des actifs naturels (eau, biodiversité, bancs de pêche) et sont aussi de nouvelles initiatives sur des questions telles que l'alimentation, l'énergie, l'éducation, les services ou les transports compromis, d'une pratique de gestion partagée, à l'économie et à la solidarité écologiques, d'assistance, communautaires ou sociales. La revue bibliographique montre que le retour aux biens communs proposé dans le texte est une alternative pour démocratiser l'économie.

La actual economía capitalista, patriarcal y cada vez más financiada tiene compartimentos (social, ambiental o de infraestructura) que reproducen su hegemonía e impiden el surgimiento de otras visiones y prácticas económicas. A la vista de estos anexos, las estrategias de las Otras Economías pueden considerarse, dentro de una gran diversidad de enfoques y contextos, una expresión de los Nuevos Comunes que busca desmantelar la sociedad y la economía de la entidad neoliberal y cada vez más autoritaria de las élites. Con ello, el artículo pretende demostrar que los nuevos bienes comunes son los antiguos comunales que aún persisten gestionando colectivamente territorios (bosques, prados, cuencas) o bienes naturales (agua, biodiversidad, bancos de pesca) y son también nuevas iniciativas en temas como la alimentación, la energía, la educación, los servicios o el transporte comprometidos, desde una práctica de gestión compartida, hasta la economía ecológica, asistencial, comunitaria o social y la solidaridad. La revisión bibliográfica muestra que el retorno a Commons propuesto en el texto es una alternativa para democratizar la economía.

\section{ÍNDICE}

Mots-clés: économie critique, nouveaux biens communs, autres économies, coopération sociale, décroissance.

Palavras-chave: Economia crítica, novos bens comuns, economias-outros, cooperação social, decrescimento.

Palabras claves: Economía crítica, nuevos bienes comunes, otras economías, cooperación social, decrecimiento.

Keywords: Critical economics, New commons, Economies-others, social cooperation, degrowth. 


\section{AUTOR}

\section{DANIEL FRANCISCO NAGAO MENEZES}

Mestre e Doutor em Direito Político e Econômico (Universidade Presbiteriana Mackenzie), PósDoutor em Direito (USP). Pós-Doutorando em Economia (UNESP-Araraquara). Professor do Programa de Pós-Graduação em Direito Político e Econômico da Faculdade de Direito da Universidade Presbiteriana Mackenzie.

nagao.menezes@gmail.com 